\title{
Income level and antibiotic misuse: a systematic review and dose-response meta-analysis
}

\author{
Narmeen Mallah $^{1,2,3,4} \cdot$ Nicola Orsini $^{1} \cdot$ Adolfo Figueiras $^{2,3,4} \cdot$ Bahi Takkouche $^{2,3,4,5}$ (D)
}

Received: 20 April 2021 / Accepted: 15 November 2021 / Published online: 30 November 2021

(c) The Author(s) 2021

\begin{abstract}
Objectives To quantify the association between income and antibiotic misuse including unprescribed use, storage of antibiotics and non-adherence.

Methods We identified pertinent studies through database search, and manual examination of reference lists of selected articles and review reports. We performed a dose-response meta-analysis of income, both continuous and categorical, in relation to antibiotic misuse. Summary odds ratios (ORs) and their 95\% confidence intervals (CIs) were estimated under a random-effects random effects model.

Results Fifty-seven studies from 22 countries of different economic class were included. Overall, the data are in agreement with a flat linear association between income standardized to socio-economic indicators and antibiotic misuse (OR per 1 unit increment $=1.00, p$-value $=0.954, p$-value non-linearity $=0.429)$. Data were compatible with no association between medium and high income with general antibiotic misuse (OR 1.04; 95\% CI 0.89, 1.20 and OR 1.03; 95\% CI 0.82, 1.29). Medium income was associated with $19 \%$ higher odds of antibiotic storage (OR 1.19; 95\% CI 1.07, 1.32) and 18\% higher odds of any aspect of antibiotic misuse in African studies (OR 1.18; 95\% CI 1.00, 1.39). High income was associated with $51 \%$ lower odds of non-adherence to antibiotic treatment (OR 0.49; 95\% CI 0.34, 0.60). High income was also associated with $11 \%$ higher odds of any antibiotic misuse in upper-middle wealth countries (OR 1.11; 95\% CI 1.00, 1.22).

Conclusions The association between income and antibiotic misuse varies by type of misuse and country wellness. Understanding the socioeconomic properties of antibiotic misuse should prove useful in developing related intervention programs and health policies.
\end{abstract}

Keywords Income $\cdot$ Antibiotics $\cdot$ Misuse $\cdot$ Meta-analysis $\cdot$ Dose-response

Bahi Takkouche

bahi.takkouche@usc.es

1 Department of Global Public Health, Karolinska Institutet, Stockholm, Sweden

2 Department of Preventive Medicine, University of Santiago de Compostela, Santiago de Compostela, Spain

3 Centro de Investigación Biomédica en Red de Epidemiología y Salud Pública (CIBER-ESP), Madrid, Spain

4 Health Research Institute of Santiago de Compostela (IDIS), Santiago de Compostela, Spain

5 Department of Preventive Medicine, Faculty of Medicine, University of Santiago de Compostela, 15782 Santiago de Compostela, Spain

\section{Introduction}

The misuse of antibiotics is defined as the intake of these drugs without medical advice (self-prescription) or their use when prescribed by the physician but without compliance with the physician's instructions for treatment regimen in terms of timing, dosage and duration [1,2]. It is a salient problem worldwide, irrespective of the country economy and wealth. Antibiotic misuse has led to antibiotic resistance, a universal public health problem with high socioeconomic and clinical burdens. Different systematic reviews and meta-analyses reported the high prevalence of antibiotic misuse. In their study, Morgan et al. reviewed publications from five continents and concluded that the use of antibiotics without prescription is wide-reaching and accounts for 19 to $100 \%$ of antibiotic use outside Northern Europe and North America [3]. Gualano et al. also reported that almost half 
of the individuals stop taking antibiotics upon improvement [4]. Another review estimated that the mean use of leftover antibiotics worldwide is $29 \%$, and that of compliance with antibiotic therapy is only $62 \%$ [5]. A recent meta-analysis of studies from low- and middle- income countries found that the pooled prevalence of non-prescribed use of antibiotics is considerably high (78\%) in these countries [6]. Antibiotic misuse is also frequent in high- income countries, including the United States where the prevalence of antibiotic use without prescription is as high as $66 \%$ in some instances, and that of storage of antibiotics for future use ranges between 14 and $48 \%$ [7].

Antibiotic resistance causes at least 700,000 annual deaths worldwide [8], more than 35,000 in the United States alone [9]. A similar record is registered in Europe [10]. The impact of antibiotics resistance on the economy is also expanding with disturbing figures [11]. By 2050, the annual mortality rate from antibiotic resistance is projected to exceed that of major causes of death like cancer and diabetes [8], and the provoked economic shortfalls will be as large as that of the 2008-2009 global financial crisis [12].

Several determinants of antibiotic misuse have been identified. These are mainly sociodemographic, including female gender, young adults and elderly, low educational level, difficult access to the healthcare system, unaffordability of the cost of physicians visit and accessibility to antibiotics [7, 13, 14].

In 2012, a narrative review report about self-medication with antibiotics in developing countries analysed data of five studies and concluded that middle income is associated with antibiotic misuse [15]. Studies that evaluated the association of income with antibiotic misuse showed divergent results. Some studies reported up to six-fold increased odds of misuse in high- income individuals [16, 17], while other studies did not find any association [18-20], or detected lower odds of misuse $[21,22]$. It is also unclear whether the association between income and antibiotic misuse holds at different social classes and in regions with different levels of access to healthcare and in which regulations about antibiotic dispensing might vary. To the best of our knowledge, there is no meta-analysis that evaluates the association of income with antibiotic misuse worldwide.

To address this gap, we aimed in this study to carry out a meta-analysis of the association of income with antibiotic misuse. We present analyses standardized for socioeconomic indicators.

\section{Materials and methods}

PRISMA guidelines were followed for the conduct and reporting of this meta-analysis, and the study protocol was registered in the PROSPERO database (ID: number deleted for blinding purposes). The outcome, antibiotic misuse, was defined as the use or purchase of non-prescribed antibiotics to treat oneself or another person, storage of leftover antibiotics, or nonadherence to the physicians' instructions regarding the dosage, timing and treatment duration. Storage of antibiotics facilitates access to them and therefore is the first step towards their use without prescription [23].

\section{Literature search and study selection}

Medline, EMBASE, Conference Proceedings Citation IndexScience, the Open Access Theses and Dissertations, and the five regional bibliographic databases of the World Health Organization (WHO) were searched since their inception until January 2021. The following search syntax was applied in Medline: (Socioeconomic Factors OR income) AND (antibiotic*) AND ((drug storage [MeSH]) OR (compliance) OR (adherence) OR (Nonprescription Drugs/administration \& dosage* [MeSH]) OR (misuse) OR (irrational use) OR (left-over)) and adapted for the other databases. We complemented our search by using free text words as follows: antibiotics AND (misuse OR "unprescribed use" OR leftover OR "adherence to treatment") AND (income OR "socioeconomic status" OR "socioeconomic level"). The reference lists of related reviews [3-7, 13-15, 24, 25] and those of included studies were manually checked to supplement database searches. The search was carried out without any language or date restrictions.

Studies that met the following criteria were included: (1) reporting at least two levels of income with defined boundaries as an exposure, and (2) providing Odds Ratio (OR) or Risk Ratio (RR) and their 95\% Confidence Interval (CI) as a measurement of the association of income and misuse of antibiotics by the general population, or sufficient data for their calculation.

\section{Data extraction and synthesis}

From each included study, we extracted: (1) general study characteristics: author's last name and year of publication, study period, participants characteristics (age and gender), and country where the study took place, (2) exposure: levels of monthly income, (3) measures of association: for each income level: number of subjects who practiced antibiotic misuse, total sample size, adjusted ORs and 95\%CIs, and restriction, adjustment, or matching variables. When adjusted ORs were not provided, the crude estimates were registered, and (4) Type of antibiotic misuse: use without prescription, non-adherence, and storage of antibiotic leftover. When data was were provided for more than one type of antibiotic misuse, we extracted the data of all types of misuse. When the number of events of antibiotic misuse per income level was not available, we contacted the authors to 
request this information, but no reply was received [26-28]. We then deemed the number of events missing for those studies. We also inquired about the reference group used in a sub-analysis of one study [29], but due to lack of answer, we did not consider that subgroup.

We standardized the income to country-specific socioeconomic indicators using two approaches. In the first approach, income was standardized to gross domestic product (GDP) per capita based on purchasing power parity (PPP) [30]. PPP is a currency conversion rate that is used to equalise the purchasing power of different monetary units. It allows to compare standards of living and economic productivity between countries [31]. In the second approach, the income level was standardized to the adjusted net national income per capita, expressed in US dollars [30]. The historical country-specific values of PPP, GDP per capita based on PPP, and adjusted net national income per capita were extracted from their specific portals in the World Bank [31-33].

Besides data reported in the studies, the classification of countries by economy [34], geographic distribution [35], and literacy rate [36] was obtained.

\section{Statistical analysis}

Studies included in this meta-analysis presented income categorized into 2 to 6 levels, with an average of 3 levels. As an estimate of the dose, we used the midpoint assigned to an estimated contrast given the upper and lower boundaries of the income.

We carried out dose-response meta-analysis of income standardized to: (1) gross domestic product (GDP) per capita based on (PPP) and (2) adjusted net national income per capita.

The dose-response meta-analysis was performed using a one-stage mixed-effects model taking into account heterogeneity across studies [37, 38].

We first used a linear function to estimate a summary OR of antibiotic misuse associated with an increase of 1 unit in income. We next flexibly modelled income using restricted cubic splines with 3 knots fixed at 10th, 50th and 90th percentiles of its distribution. Tests of hypothesis about the regression coefficients of the dose-response model were conducted using a large sample Wald-type test. To facilitate tabular presentation of the summary odds ratios, we further categorized income into tertiles using the lowest as referent.

We stratified the dose-response analysis by type of antibiotic misuse (unprescribed use, storage of leftover, non-adherence); WHO geographic classification, country economy (low wealth, lower-middle wealth, upper-middle wealth and high-wealth); literacy rate $(\geq 90 \%,<90 \%)$; exposure ascertainment (use of pretested or validated questionnaire; untested questionnaire or not reported); comparability (control for age, sex, educational level and household size; incomplete control); and publication year $(\leq 2015,>2015)$. In 2015, WHO published the global action plan to combat the problem of antibiotic resistance [39].

\section{Quality appraisal}

As all studies retrieved were eventually of cross-sectional nature, we appraised the quality of the studies using the Newcastle-Ottawa Scale for cross-sectional studies [40]. One point was given for the fulfilment of each of the following criteria: (1) well- defined target population; (2) reported response rate; (3) well described and appropriate statistical analysis; (4) justified sample size; (5) studies adjusted, matched or restricted for age, sex, educational level and household size; (6) use of previously tested or validated questionnaire; and (7) outcome ascertainment carried out using external assessment in addition to self-reporting. When information on a specific criterion was not given, it was graded with 0 point. The grades across items were then summed to obtain a quality score of a maximum of seven points. Two epidemiologists ( $N M$ and $A F$ ) carried out the quality assessment, and disagreements were resolved by referring to a third epidemiologist (BT).

\section{Publication bias}

Publication bias was checked visually using funnel plot and formally through Egger's test [41], and the trim-and-filltrim and fill method [42].

\section{Results}

\section{Literature search and study}

Figure 1 represents the flow diagram of the selection of studies about income level and misuse of antibiotics. One thousand four hundred fifty-three publications were identified from the literature search, out of which 314 were selected for full- text review (Fig. 1). Fifty-one studies published between 2001 and 2021 met our inclusion criteria (Table 1). Five studies provided data for several types of misuse [20, $27,28,43,44]$. We treated each type of misuse as a separate study, making a total of 57 studies introduced in the dose-response analysis. All studies were of cross-sectional design. They involved a total population of 51,008 individuals from 22 countries and 18,094 events of antibiotic misuse. Forty-nine studies were published in English, one in Spanish [45] and one in Croatian [46]. 
Fig. 1 Flow diagram of the selection of studies about income level and misuse of antibiotics

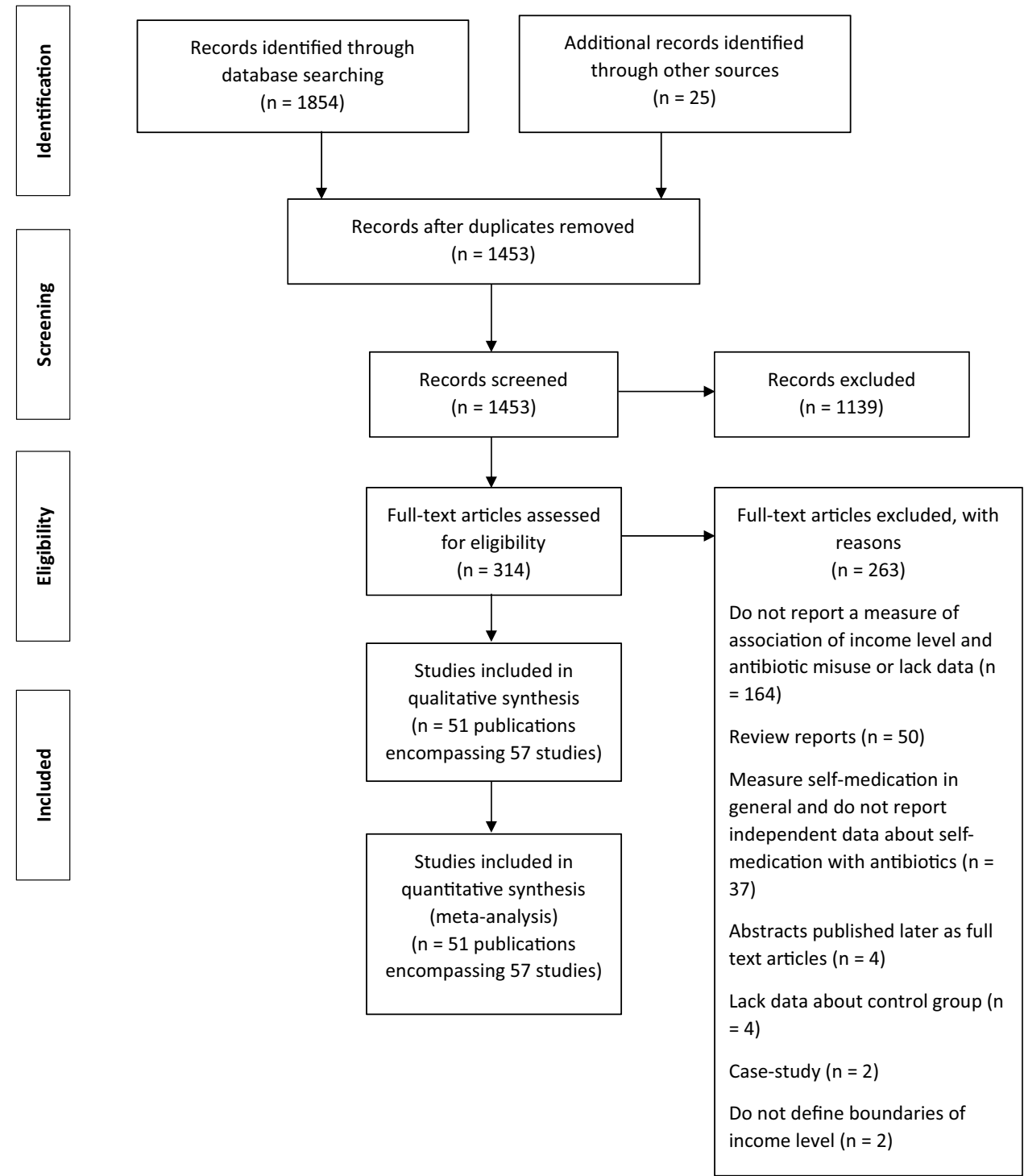

\section{Income level and antibiotic misuse: continuous analysis}

Overall, the data from these 57 studies were compatible with a flat linear association between income standardized to GDP per capita based on PPP and antibiotic misuse $(\mathrm{OR} 1.00 ; p$-value $=0.954, p$-value non-linearity $=0.452$ ). Similar results were obtained for the association of income standardized to adjusted net national income per capita and antibiotic misuse (OR 1.00; $p$-value $=0.940$ ).

As a graphical presentation of the trend, Fig. 2 shows the estimated summary odds ratio of antibiotic misuse conferred by income standardized to GDP per capita based on PPP.

\section{Income level and antibiotic misuse: categorical and stratified analysis}

In the categorical approach of income standardized to GDP per capita based on PPP, overall, as compared to low (1st tertile), no association between income and general antibiotic misuse was observed: medium income (2nd tertile): OR 1.03; 95\% CI 0.82, 1.29 (Table 2).

Stratified analysis revealed that medium income was associated with $19 \%$ higher odds of storage of antibiotics (OR 1.19; 95\% CI 1.07, 1.32),); nonetheless, we did not observe any significant association between high income and this type of misuse (OR 1.04; 95\% CI 0.92, 1.17). It is noteworthy to mention that storage of antibiotics was OR 1.04; 95\% CI 0.89, 1.20, and high income (3rd tertile): 


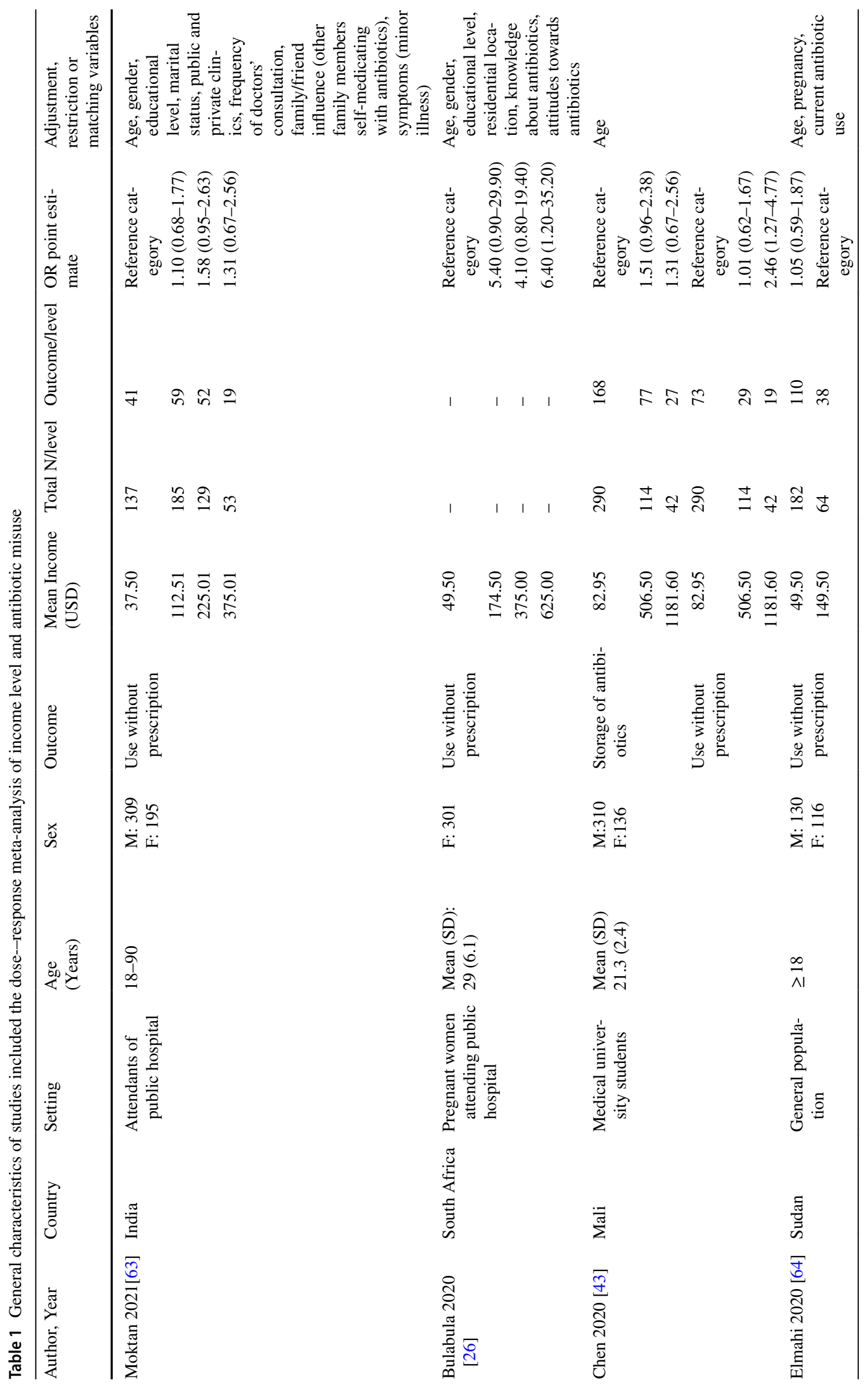




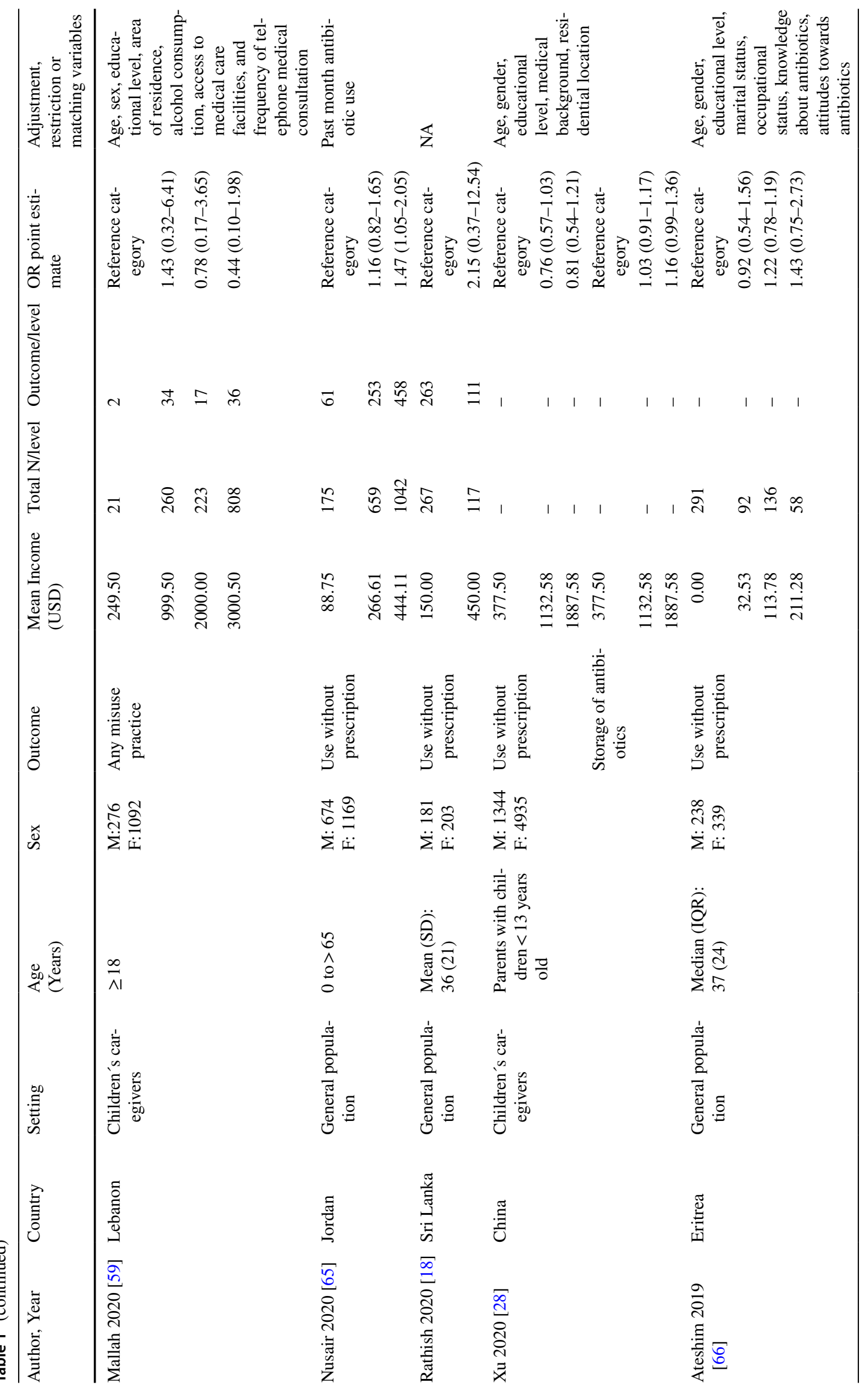




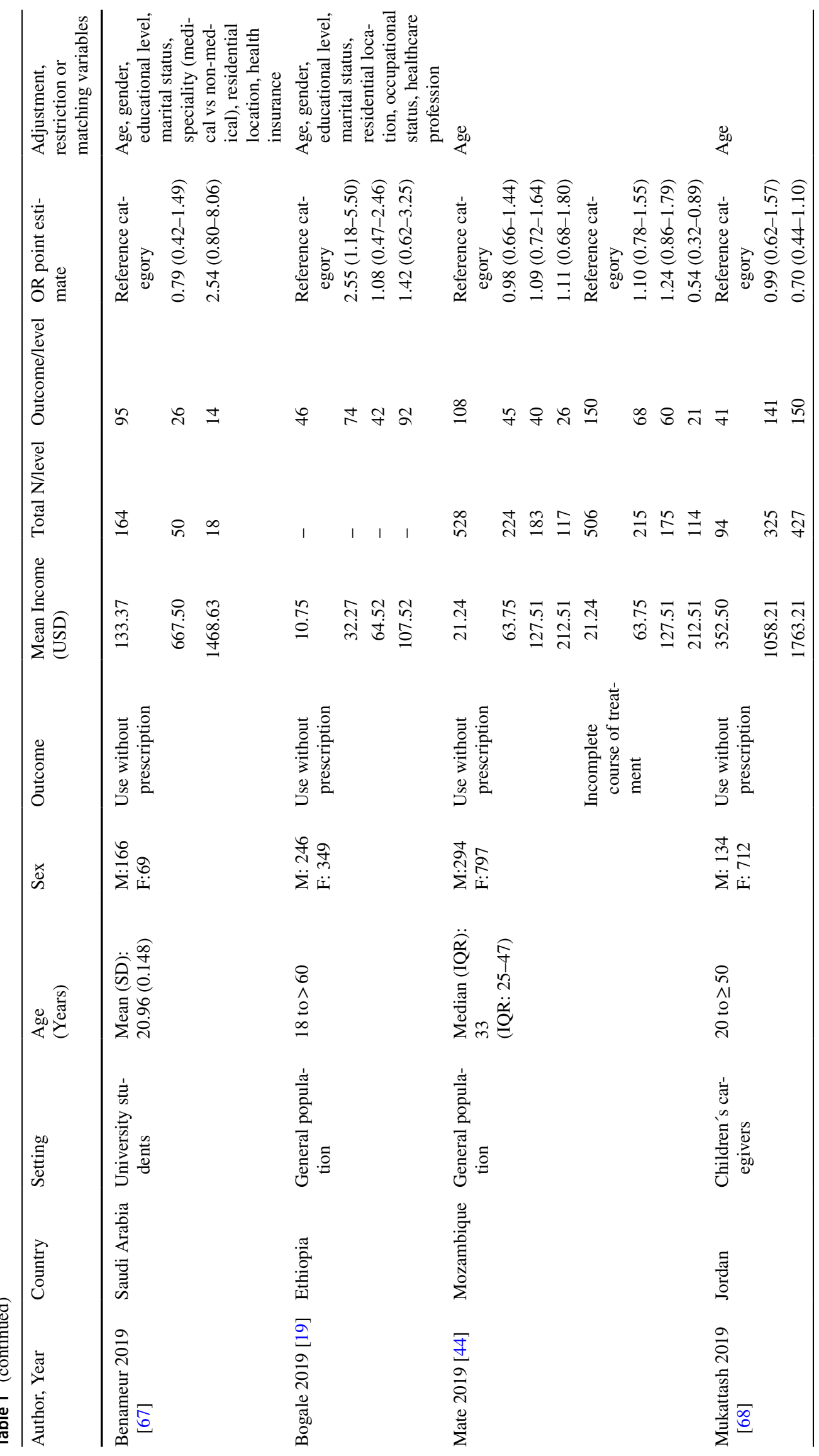




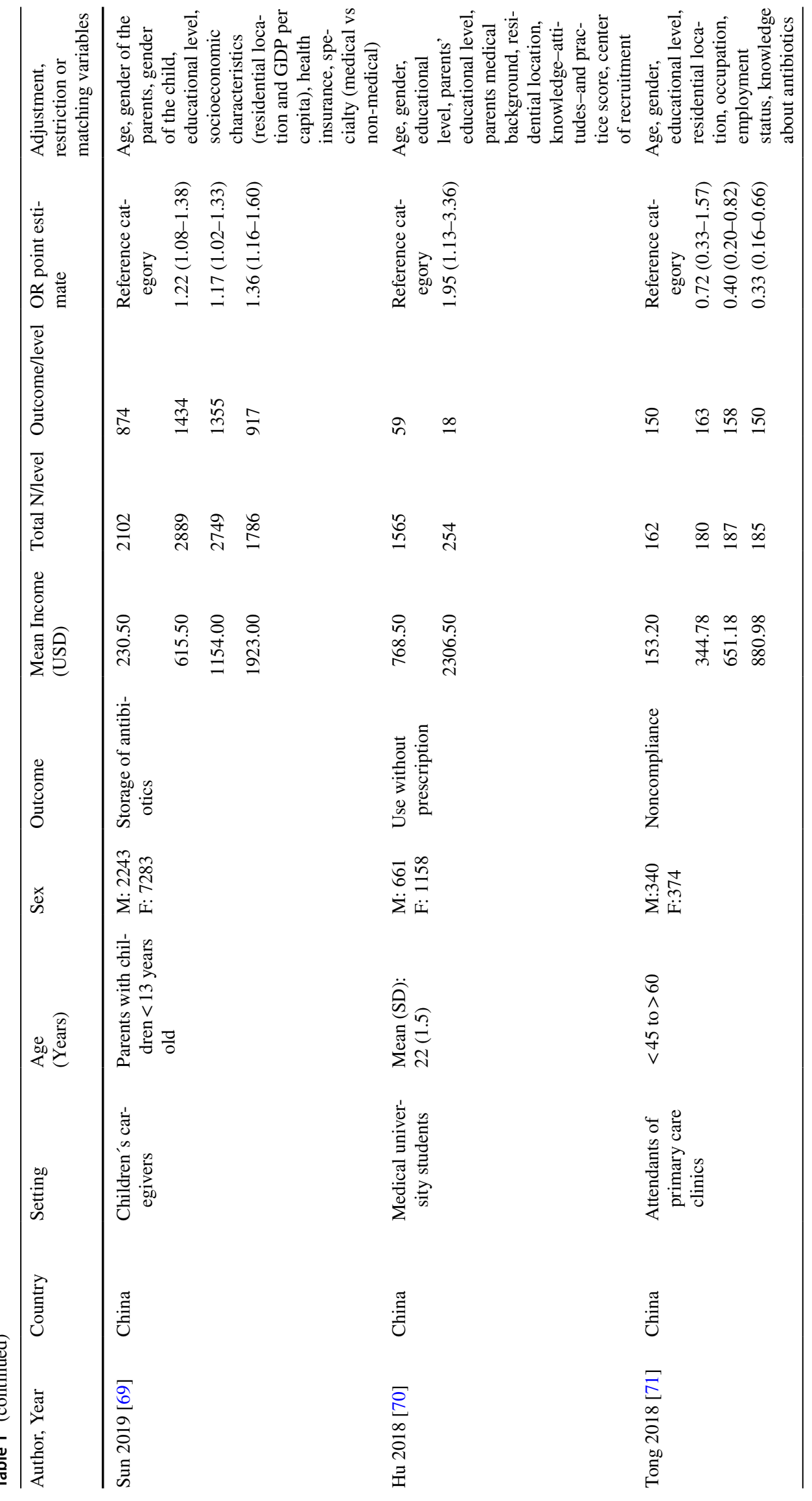




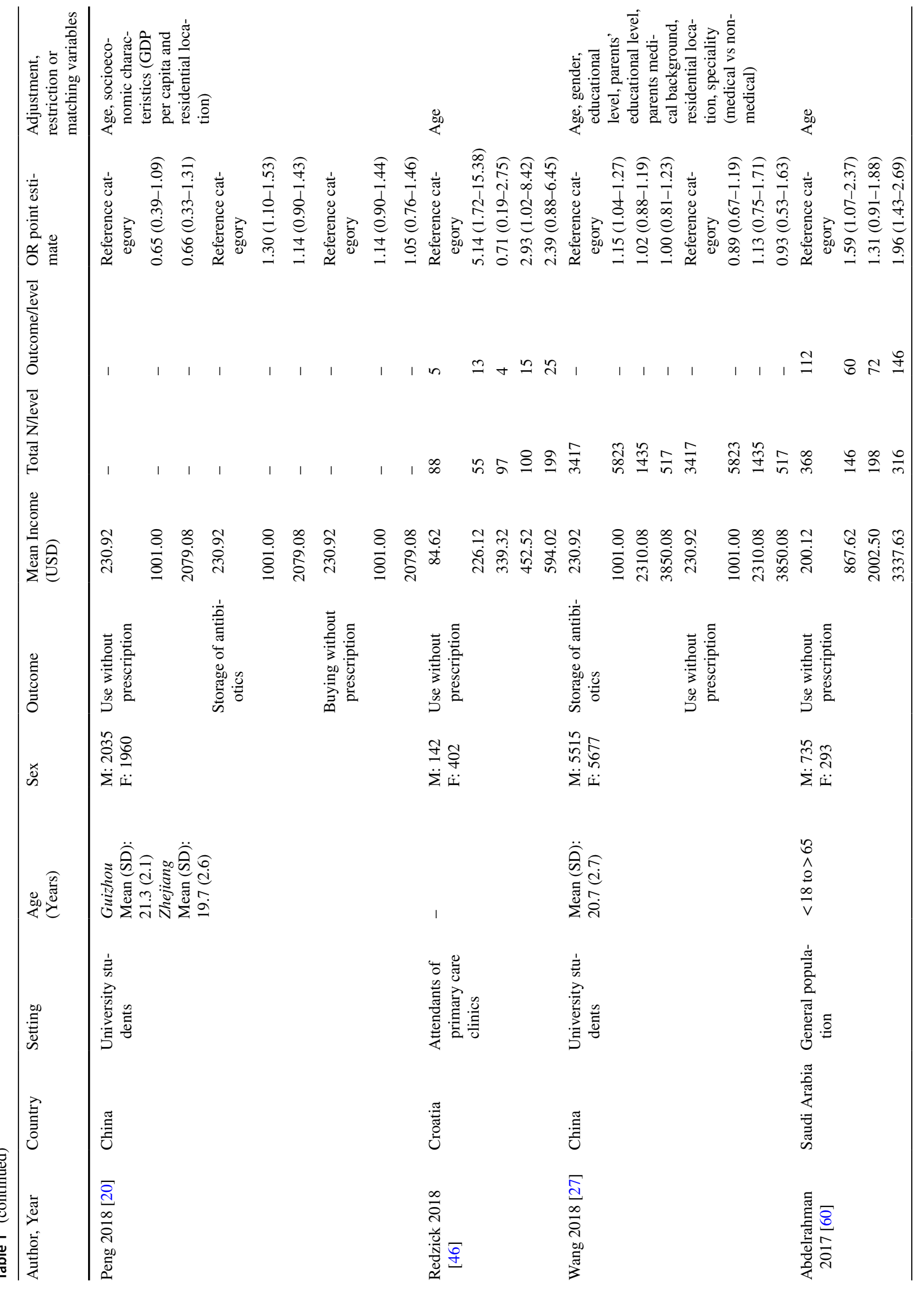




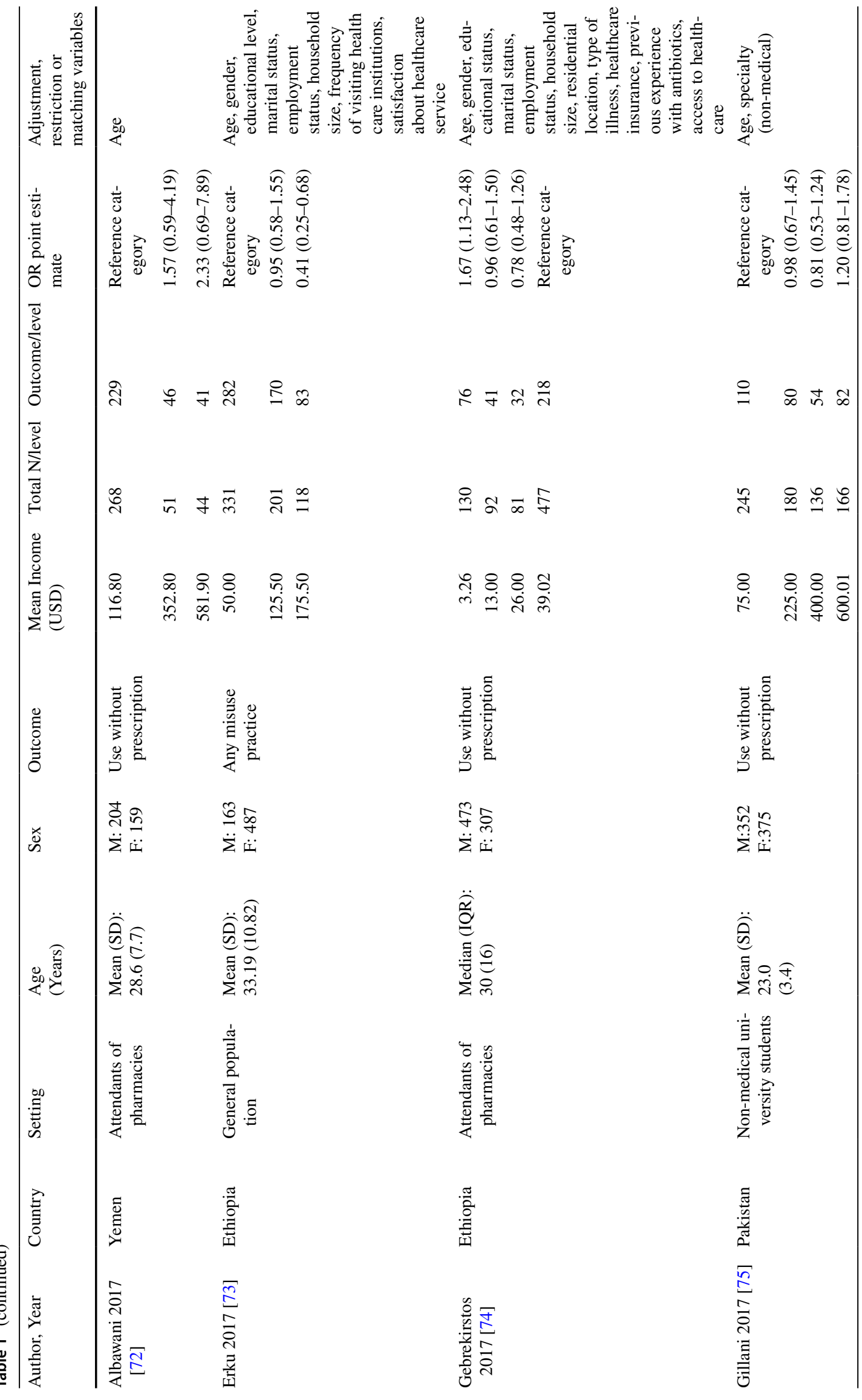




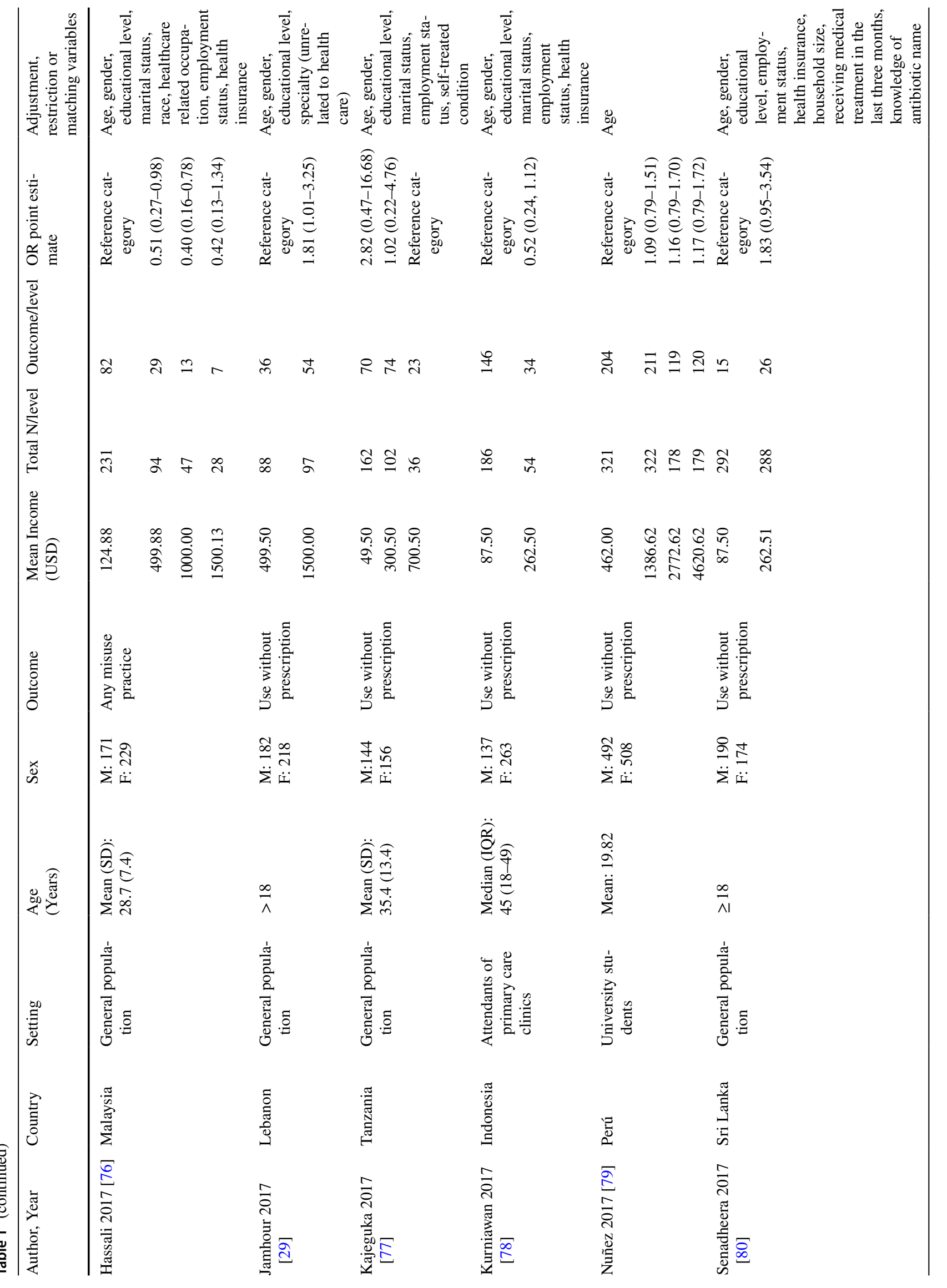




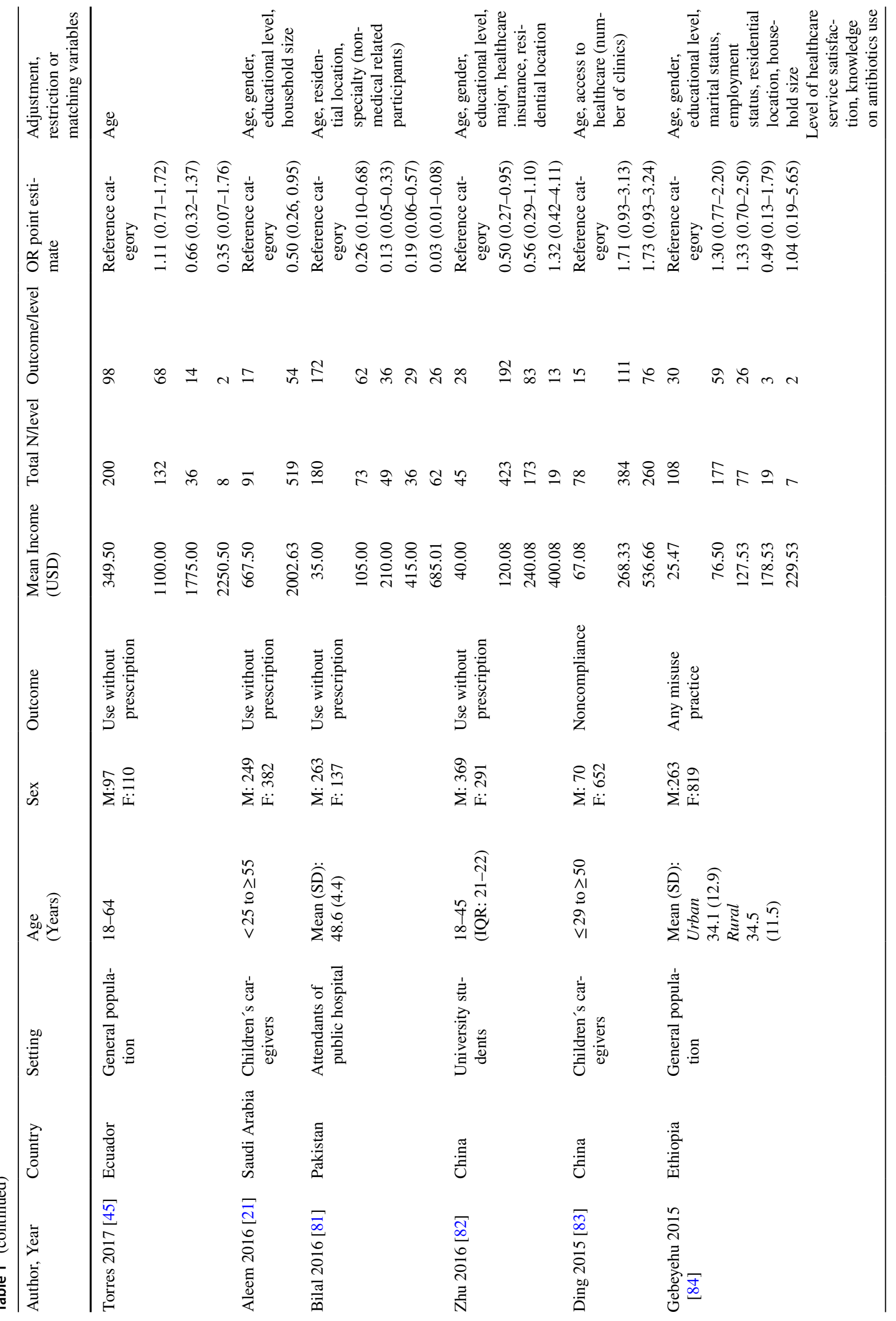




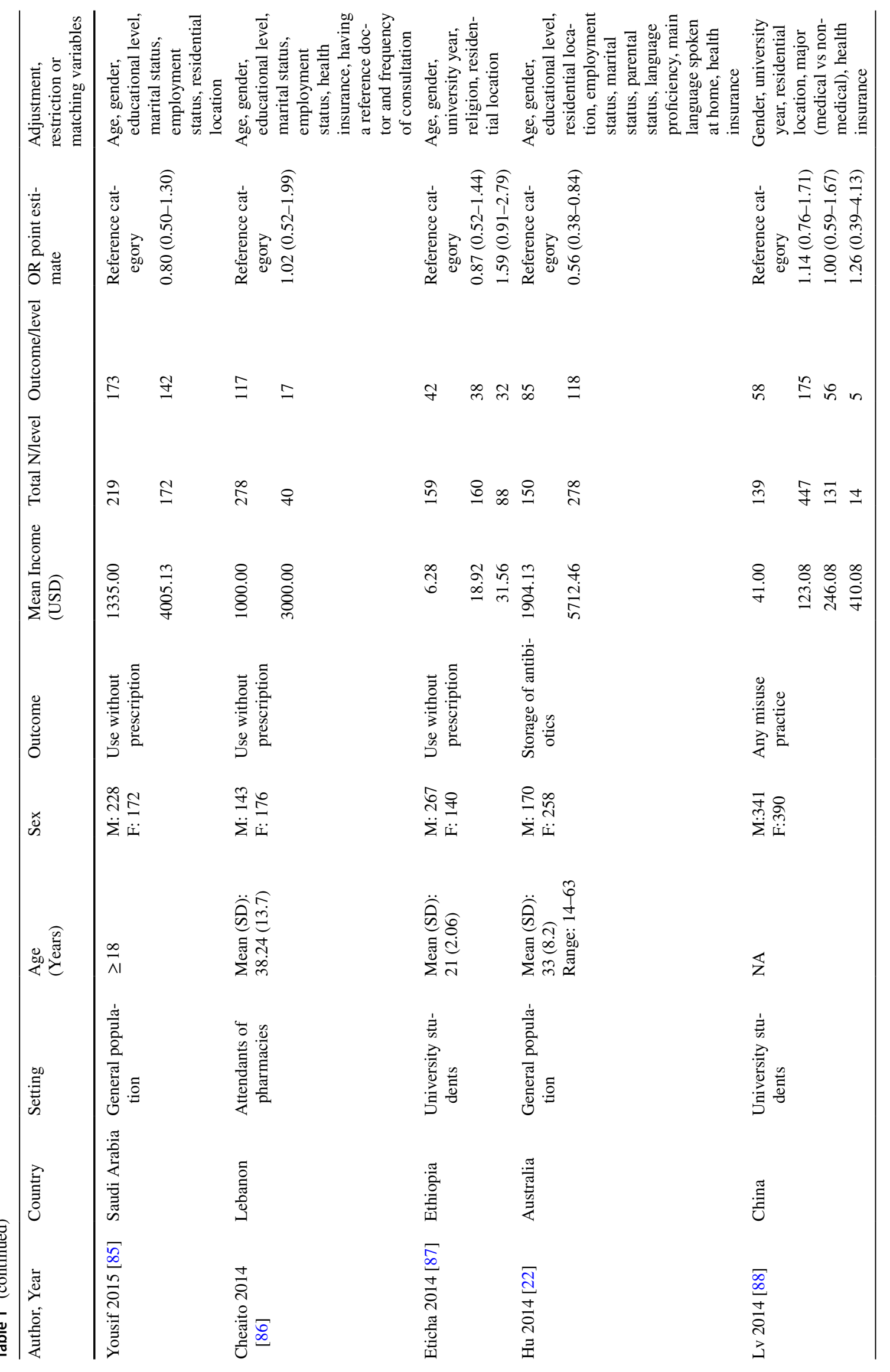




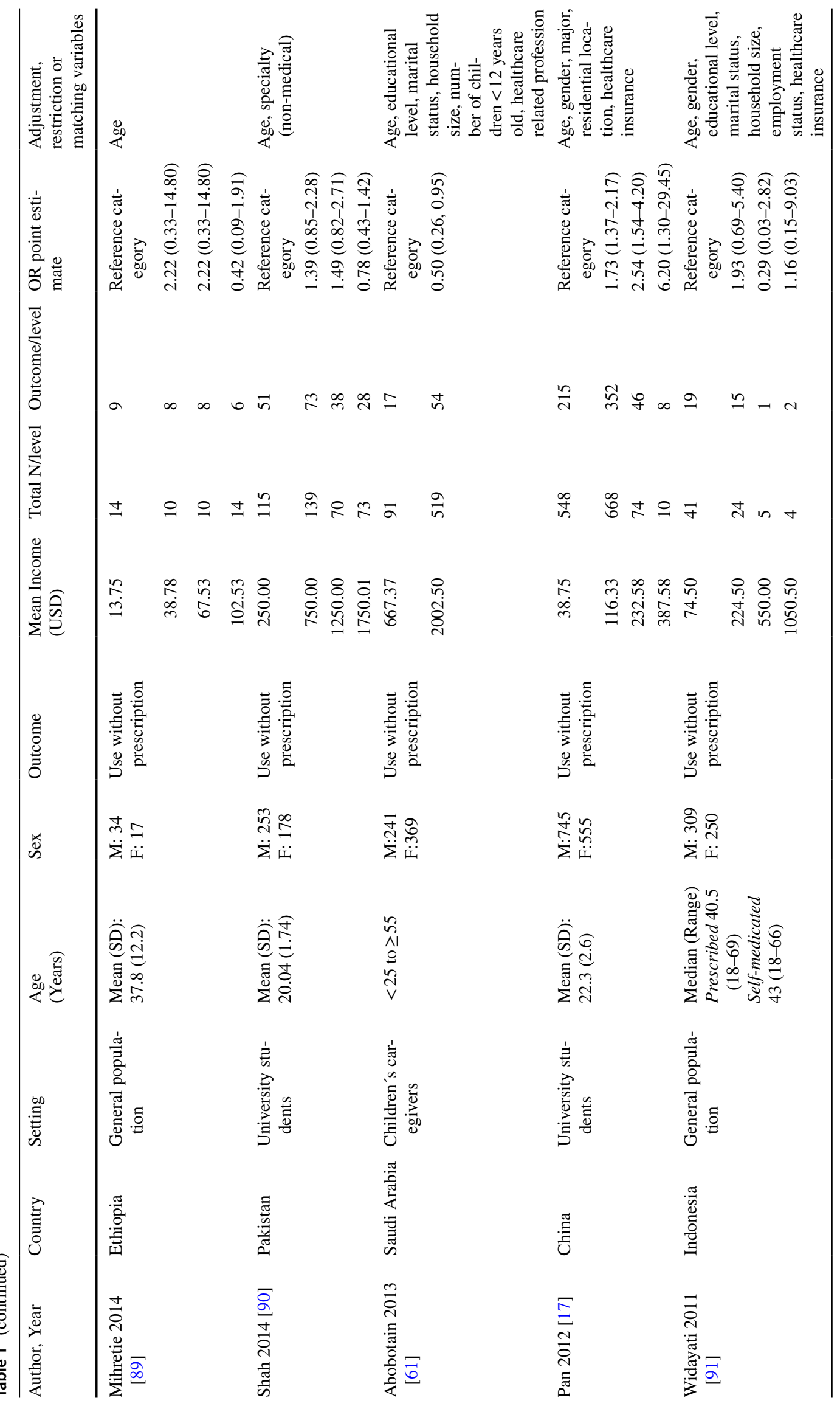




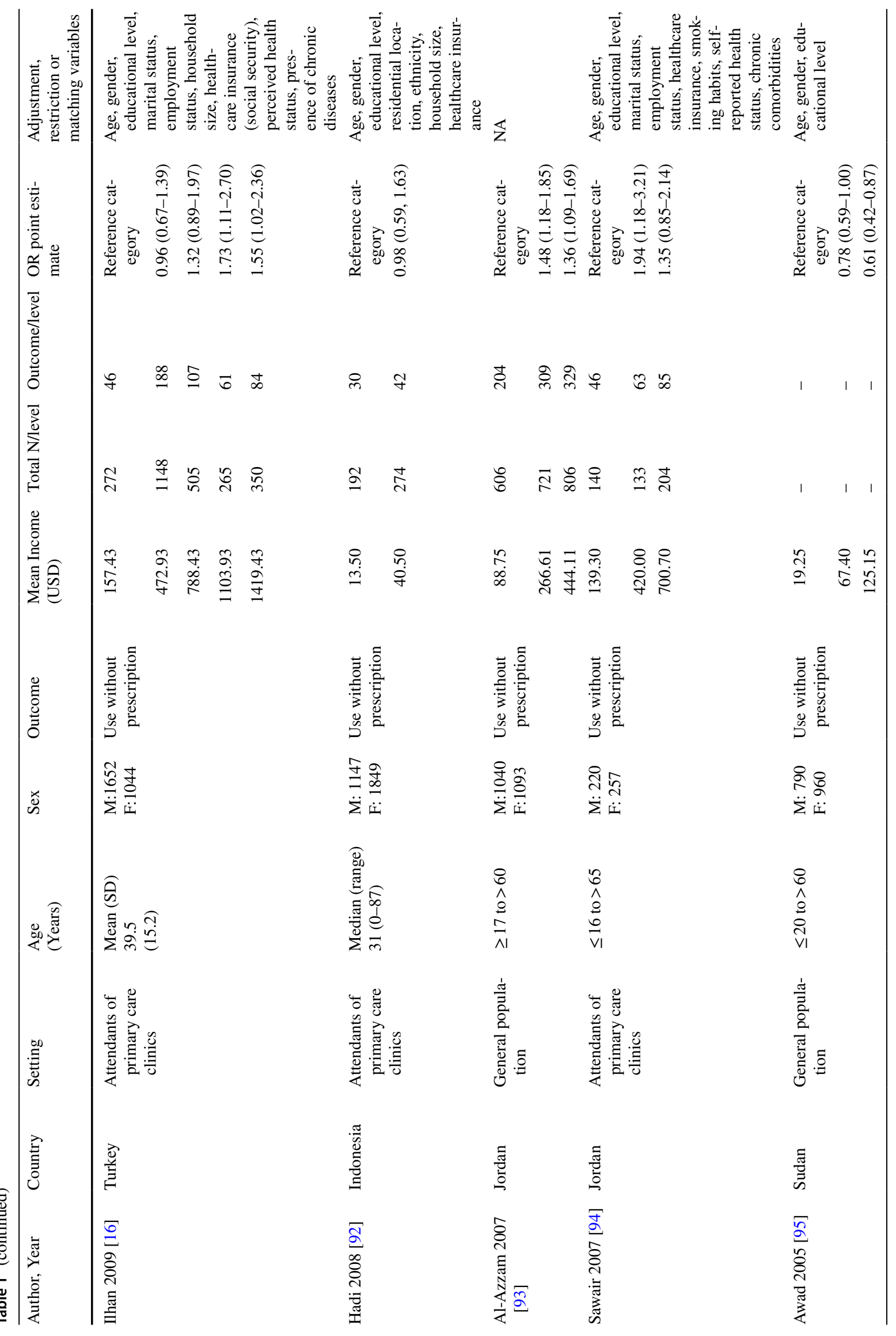




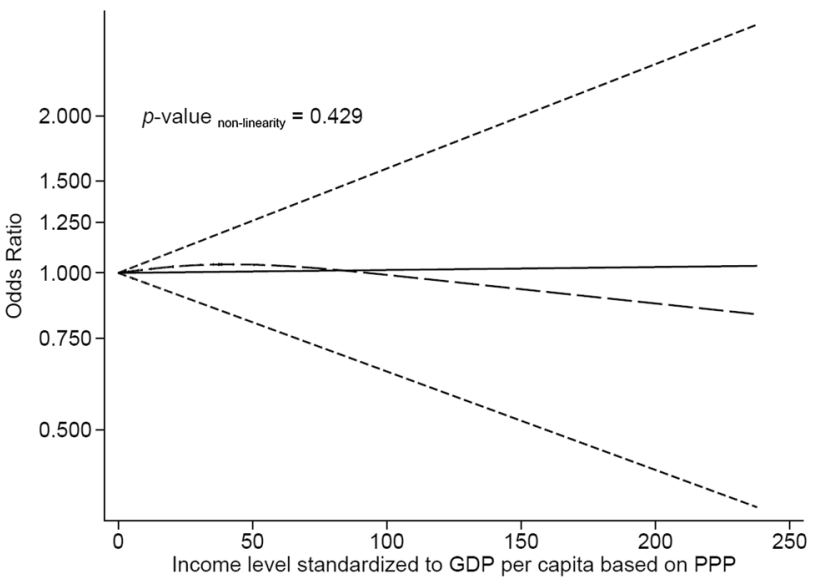

Fig. 2 Trend of the association of income level standardized to GDP per capita based on PPP and antibiotic misuse. Solid line represents the linear trend. Long-dashed line represents the non-linear restricted cubic spline approach. Short-dashed lines represents 95\% CI evaluated in five studies carried out in China [20, 27, 28, $43,44]$ and in a sixth study that was undertaken in Australia but involved Chinese immigrants [22]. High income was associated with $51 \%$ lower odds of non-adherence to antibiotics treatment (OR $0.49,95 \%$ CI $0.34,0.70$ ) (Table 2). When restricting the analysis to low-wealth countries, high- income individuals were at $11 \%$ higher odds of antibiotic misuse than those with low income in upper-middle wealth countries (OR 1.11; 95\% CI 1.00, 1.22) (Table 2). Our findings also suggested an association between medium-income medium income level and antibiotic misuse in African countries (OR 1.18; 95\% CI 1.00, 1.39) (Table 2). After 2015, the odds of misuse of antibiotics in medium- income individuals increased when compared with studies undertaken until 2015 $\left(\mathrm{OR}_{\text {until } 2015} 0.95 ; 95 \%\right.$ CI 0.75, 1.20 and $\mathrm{OR}_{\text {after } 2015} 1.12$; $95 \%$ CI $0.99,1.26)$. Similar findings were obtained for high- income individuals $\left(\mathrm{OR}_{\text {until } 2015} 0.91 ; 95 \% \mathrm{CI} 0.62\right.$, 1.35 and OR $_{\text {after } 2015} 1.15 ; 95 \%$ CI 0.93, 1.41) (Table 2).
Table 2 Meta-analysis of the association of income level represented as units of GDP per capita based on PPP with antibiotic misuse

\begin{tabular}{|c|c|c|c|}
\hline & $\begin{array}{l}\text { Number of } \\
\text { studies }\end{array}$ & $\begin{array}{l}\text { Medium income OR } \\
(95 \% \mathrm{CI})\end{array}$ & High income OR $(95 \% \mathrm{CI})$ \\
\hline All studies & 57 & $1.04(0.89,1.20)$ & $1.03(0.82,1.29)$ \\
\hline \multicolumn{4}{|l|}{ Type of misuse } \\
\hline Use without prescription & 43 & $1.06(0.87,1.28)$ & $1.07(0.84,1.37)$ \\
\hline Storage of antibiotics & 6 & $1.19(1.07,1.32)$ & $1.04(0.92,1.17)$ \\
\hline Non-adherence & 3 & $1.10(0.89,1.35)$ & $0.49(0.34,0.70)$ \\
\hline \multicolumn{4}{|l|}{ Country economy } \\
\hline Low & 16 & $1.02(0.83,1.24)$ & $0.90(0.59,1.37)$ \\
\hline Lower-middle & 11 & $1.14(0.73,1.80)$ & $0.92(0.46,1.84)$ \\
\hline Upper-middle & 25 & $1.17(0.91,1.49)$ & $1.11(1.00,1.22)$ \\
\hline High & 5 & $0.90(0.44,1.85)$ & $1.04(0.33,3.28)$ \\
\hline \multicolumn{4}{|l|}{ WHO Region } \\
\hline African & 14 & $1.18(1.00,1.39)$ & $0.96(0.67,1.38)$ \\
\hline Eastern Mediterranean & 17 & $0.92(0.65,1.32)$ & $0.95(0.58,1.57)$ \\
\hline South-East Asian & 6 & $1.11(0.62,2.00)$ & $1.53(0.81,2.92)$ \\
\hline Western Pacific & 16 & $0.99(0.82,1.20)$ & $1.05(0.92,1.19)$ \\
\hline \multicolumn{4}{|l|}{ Survey year } \\
\hline Until 2015 & 29 & $0.95(0.75,1.20)$ & $0.91(0.62,1.35)$ \\
\hline After 2015 & 28 & $1.12(0.99,1.26)$ & $1.15(0.93,1.41)$ \\
\hline \multicolumn{4}{|l|}{ Literacy rate } \\
\hline$<90 \%$ & 20 & $1.03(0.82,1.29)$ & $1.02(0.68,1.54)$ \\
\hline$\geq 90 \%$ & 37 & $1.09(0.93,1.28)$ & $1.02(0.84,1.23)$ \\
\hline \multicolumn{4}{|c|}{ Pre-tested or validated questionnaire } \\
\hline No & 10 & $1.02(0.51,2.06)$ & $0.90(0.34,2.36)$ \\
\hline Yes & 47 & $1.06(0.91,1.24)$ & $1.04(0.85,1.27)$ \\
\hline \multicolumn{4}{|l|}{ Adjustment } \\
\hline Incomplete & 47 & $1.09(0.95,1.24)$ & $1.05(0.84,1.31)$ \\
\hline Complete & 10 & $0.90(0.71,1.15)$ & $0.60(0.30,1.23)$ \\
\hline \multicolumn{4}{|l|}{ Quality Score } \\
\hline Lower quality ( $\leq 3$ points) & 24 & $0.99(0.75,1.31)$ & $1.09(0.72,1.66)$ \\
\hline Higher quality ( $>3$ points) & 33 & $1.04(0.86,1.25)$ & $1.03(0.81,1.31)$ \\
\hline
\end{tabular}


No meaningful difference in the odds of antibiotic misuse by medium- and high- income individuals was observed when countries were grouped according to literacy rate (Table 2).

The categorical approach of income standardized to net national income per capita showed similar results to that of income standardized to GDP per capita based on PPP (data not shown).

\section{Methodological characteristics of the studies}

Restricting the analysis to those studies that used pretested or validated questionnaires did not yield any substantial modification in the pooled OR estimates $\left(\mathrm{OR}_{\text {medium }} 1.06\right.$; 95\% CI $0.91,1.24$ and $\mathrm{OR}_{\text {high }} 1.04 ; 95 \%$ CI $0.85,1.27$ ) (Table 2).

Studies that incompletely controlled for sex, age, educational level and household size showed higher pooled estimates than those with complete control of those variables in medium income $\left(\mathrm{OR}_{\text {incomplete }} 1.09 ; 95 \%\right.$ CI $0.95,1.24$ and $\left.\mathrm{OR}_{\text {complete }} 0.90 ; 95 \% \mathrm{CI} 0.71,1.15\right)$ and in high income $\left(\mathrm{OR}_{\text {incompletz }} 1.05 ; 95 \% \mathrm{CI} 0.84,1.31\right.$ and $\mathrm{OR}_{\text {complete }} 0.60$; 95\% CI 0.30, 1.23) (Table 2).

No notable difference was observed between pooled estimates from studies with lower-quality ( $\leq 3$ points) and those from studies with higher-quality score ( $>3$ points) (Table 2).

\section{Publication bias}

The funnel plot (Fig. 3) and Egger's test of the null hypothesis $(p$-value $=0.39)$ did not suggest evidence of publication bias. These findings were further confirmed by

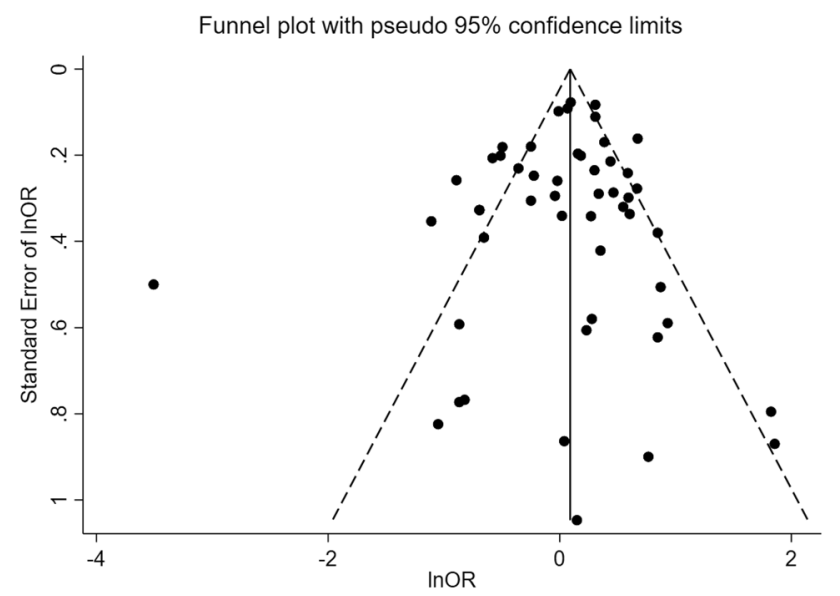

Fig. 3 Funnel plot of studies about income and antibiotic misuse the Trim-and-Fill analysis that did not yield to the addition of any study.

\section{Discussion}

Antibiotic resistance is an internationally growing multifaceted emergency that has been exacerbated by antibiotic misuse and has left devastating impact at the clinical, health and socio-economic levels. If not controlled, antibiotic resistance will convert into the major cause of death in 2050 [8].

To the best of our knowledge, this is the first meta-analysis that assesses the dose-response association between income level and misuse of antibiotics. Our results agree well with the hypothesis of no association between income level and misuse of antibiotics. Subgroup analyses reveal a dose-response association of medium- and high- income levels with specific types of antibiotic misuse, i.e., storage of drug leftover and non-adherence, country wealth, geographic region and study period.

Our primary findings suggest that the odds of misuse of antibiotics do not differ between poor and wealthy people. This is in line with the fact that both low- and high- income individuals tend to self-medicate. On the one hand, under constrained financial resources, especially in less developed economies where access to health facilities is limited, self-medication is the only available option of healthcare [47]. By self-medicating, individuals with low income avoid expenses of medical consultation and subsequent lab tests. Low- income households report forgone care more often than those with high- income level [48]. They often cut -back basic needs and take less medication than prescribed, due to cost $[49,50]$, explaining therefore the observed higher likelihood of adherence to treatment by high- income than by low-income individuals. On the other hand, people with high-income level tend to medicate themselves as they have easier access to sources of information including internet to seek health information [51], can afford purchasing nonreimbursed medicines, and have more social support that increases their access to unprescribed medicines including through sharing with families and friends [52].

Our dose-response meta-analysis also showed that medium- income individuals have higher odds of storing antibiotic leftover than those with low income. This could be related to higher financial affordability by medium-income medium income individuals to purchase and store antibiotics. Our results also show a higher likelihood of misuse by high-income individuals in upper-middle wealth countries. Consistent with our findings, an earlier report about the economy of self-medication in general, indicated that the demand for self-medication declines with rising the income level of high- income individuals, but increases with 
increasing the income of low-income individuals, resulting in a null pooled effect between income and self-medication [47].

We also reported that medium- income individuals in Africa have higher chances of antibiotic misuse, probably due to the poor enforcement of antibiotic dispensing regulations in those regions.

We observed a marginal increase in the odds of misuse of antibiotics by medium- income and high- income individuals after 2015 than before this period. This could be related to two main motives;: first, as concluded by WHO in its report Global Spending on Health, the expenditure on health is growing faster than economies, leading to a doubling of the out-of-pocket spending and very large differences between high- and low-wealth countries concerning health expenditure [53], second, not all countries have developed and implemented sufficient measures to control the dispensing of antibiotics, and thus people with greater financial resources continued using antibiotics without prescription. A recent review report indicated that more than half of the antibiotics worldwide are dispensed without prescription [54]. Consequently, the WHO placed a new urgent call to control antibiotics resistance crisis on 2019 [55].

The findings of this meta-analysis are unlikely to be affected by publication bias as revealed by the negative result of Egger's test and the trim-and-fill analysis that did not suggest imputation of any additional study.

This meta-analysis suffers from several limitations. All eligible studies were of cross-sectional design, which, theoretically, limited any causal inference. However, income is a relatively stable variable through time and, which mitigates this limitation. Furthermore, only one-fifth of included studies performed a complete control for socio-demographic variables, and higher OR estimates were obtained from studies with incomplete adjustment than in studies with complete adjustment. This reveals that our findings could be overestimated due to incomplete adjustment. Additional studies that control adequately for all potentially related socio-demographic variables are needed to confirm our results. Also, one-sixth of studies did not employ a pretested or validated questionnaire to ascertain the exposure and the outcome. However, this was unlikely to affect our results as constraining the analysis to the remaining studies did not introduce any change in the overall effect.

Our analysis was based on random-effect models to account for heterogeneity between studies [56-58]. Heterogeneity was expected in our study due to difference in the defined levels of income, period of antibiotic use (for example, use in the past month [59], past 3 months [60] and past year [61]), and settings. Experts in meta-analysis emphasize that heterogeneity is the expectation in any metaanalysis rather than the exception [62] and that no amount of heterogeneity is considered unacceptable as long as the inclusion criteria are clearly defined and the data are correctly analysed [56].

Understanding the socioeconomic properties of antibiotic misuse is crucial to develop related intervention programs and health policies, yet addition of high-quality studies that control for socio-demographic and socio-economic indicators are needed to confirm our findings.

Acknowledgements Mrs Narmeen Mallah received a Grant for her internship at Karolinska Institutet from Erasmus+ KA103 Erasmus European Mobility Program. The authors would like to thank to Mr. Luís Cea and Dr. Sami Ashour for their help with economic concepts.

Author contributions NM and BT conceived the research idea, carried out the literature review and extracted the data. AF participated in quality assessment of retrieved studies. NM carried out data analysis and interpretation and designed and wrote the manuscript. BT and NO supervised data analyses. All authors reviewed and revised the manuscript and approved it for publication.

Funding Open Access funding provided thanks to the CRUE-CSIC agreement with Springer Nature.

Data availability The data generated and analyzed in the meta-analysis are included in the article. The data are available by accessing the cited references.

\section{Declarations}

Conflict of interest The authors declare no conflict of interest.

Open Access This article is licensed under a Creative Commons Attribution 4.0 International License, which permits use, sharing, adaptation, distribution and reproduction in any medium or format, as long as you give appropriate credit to the original author(s) and the source, provide a link to the Creative Commons licence, and indicate if changes were made. The images or other third party material in this article are included in the article's Creative Commons licence, unless indicated otherwise in a credit line to the material. If material is not included in the article's Creative Commons licence and your intended use is not permitted by statutory regulation or exceeds the permitted use, you will need to obtain permission directly from the copyright holder. To view a copy of this licence, visit http://creativecommons.org/licenses/by/4.0/.

\section{References}

1. Centers for Disease Control and Prevention: Antibiotic use questions and answers. https://www.cdc.gov/antibiotic-use/commu nity/about/should-know.html\#anchor_1572453021219 (2019). Accessed 21 Apr 2021

2. United Nations Office on Drugs and Crime: The non-medical use of prescription drugs: Poliy direction issues. https://www.unodc. org/documents/drug-prevention-and-treatment/nonmedical-useprescription-drugs.pdf (2011). Accessed 20 Aug 2021

3. Morgan, D.J., Okeke, I.N., Laxminarayan, R., Perencevich, E.N., Weisenberg, S.: Non-prescription antimicrobial use worldwide: a systematic review. Lancet Infect. Dis. 11(9), 692-701 (2011). https://doi.org/10.1016/S1473-3099(11)70054-8

4. Gualano, M.R., Gili, R., Scaioli, G., Bert, F., Siliquini, R.: General population's knowledge and attitudes about antibiotics: a 
systematic review and meta-analysis. Pharmacoepidemiol. Drug Saf. 24(1), 2-10 (2015). https://doi.org/10.1002/pds.3716

5. Kardas, P., Devine, S., Golembesky, A., Roberts, C.: A systematic review and meta-analysis of misuse of antibiotic therapies in the community. Int. J. Antimicrob. Agents 26(2), 106-113 (2005). https://doi.org/10.1016/j.ijantimicag.2005.04.017

6. Torres, N.F., Chibi, B., Kuupiel, D., Solomon, V.P., MashambaThompson, T.P., Middleton, L.E.: The use of non-prescribed antibiotics; prevalence estimates in low-and-middle-income countries. A systematic review and meta-analysis. Arch. Public Health. 79(1), 2 (2021). https://doi.org/10.1186/s13690-020-00517-9

7. Grigoryan, L., Germanos, G., Zoorob, R., Juneja, S., Raphael, J.L., Paasche-Orlow, M.K., et al.: Use of antibiotics without a prescription in the U.S. population: a scoping review. Ann. Intern. Med. 171(4), 257-263 (2019). https://doi.org/10.7326/M19-0505

8. Wellcome Trust: Review on antimicrobial resistance. Tackling drug-resistant infections globally: Final report and recommendations. https://amr-review.org/sites/default/files/160525_Final\% 20paper_with\%20cover.pdf (2016). Accessed 21 Apr 2021

9. Centers for Disease Control and Prevention: Antibiotic resistance threats in the United States. www.cdc.gov/DrugResistance/Bigge st-Threats.html (2019). Accessed 21 Apr 2021

10. European Center for Disease Prevention and Control \& Organization for Economic Co-operation and Development: Antimicrobial resistance tackling the burden in the European Union. A Briefing note for EU/EEA countries. https://www.ecdc.europa.eu/en/antim icrobial-resistance (2019). Accessed 21 Apr 2021

11. Spellberg, B., Blaser, M., Guidos, R.J., Boucher, H.W., Bradley, J.S., Eisenstein, B.I., et al.: Combating antimicrobial resistance: policy recommendations to save lives. Clin. Infect. Dis. 52(Suppl 5), S397-428 (2011). https://doi.org/10.1093/cid/cir153

12. World Bank: Drug-resistant infections: A threat to our economic future. Washington, DC. https://documents.worldbank.org/en/ publication/documents-reports/documentdetail/323311493396993 758/final-report (2017). Accessed 21 Apr 2021

13. Alhomoud, F., Aljamea, Z., Almahasnah, R., Alkhalifah, K., Basalelah, L., Alhomoud, F.K.: Self-medication and self-prescription with antibiotics in the Middle East-do they really happen? A systematic review of the prevalence, possible reasons, and outcomes. Int J Infect Dis. 57, 3-12 (2017). https://doi.org/10.1016/j. ijid.2017.01.014

14. Torres, N.F., Chibi, B., Middleton, L.E., Solomon, V.P., Mashamba-Thompson, T.P.: Evidence of factors influencing selfmedication with antibiotics in low and middle-income countries: a systematic scoping review. Public Health 168, 92-101 (2019). https://doi.org/10.1016/j.puhe.2018.11.018

15. Ocan, M., Obuku, E.A., Bwanga, F., Akena, D., Richard, S., Ogwal-Okeng, J., et al.: Household antimicrobial self-medication: a systematic review and meta-analysis of the burden, risk factors and outcomes in developing countries. BMC Public Health 15, 742 (2015). https://doi.org/10.1186/s12889-015-2109-3

16. Ilhan, M.N., Durukan, E., Ilhan, S.O., Aksakal, F.N., Ozkan, S., Bumin, M.A.: Self-medication with antibiotics: questionnaire survey among primary care center attendants. Pharmacoepidemiol. Drug Saf. 18(12), 1150-1157 (2009). https://doi.org/10.1002/pds. 1829

17. Pan, H., Cui, B., Zhang, D., Farrar, J., Law, F., Ba-Thein, W.: Prior knowledge, older age, and higher allowance are risk factors for self-medication with antibiotics among university students in southern China. PLoS ONE 7(7), e41314 (2012). https://doi.org/ 10.1371/journal.pone.0041314

18. Rathish, D., Wickramasinghe, N.D.: Prevalence, associated factors and reasons for antibiotic self-medication among dwellers in Anuradhapura: a community-based study. Int. J. Clin. Pharm. 42(4), 1139-1144 (2020). https://doi.org/10.1007/s11096-020-01065-6
19. Bogale, A.A., Amhare, A.F., Chang, J., Bogale, H.A., Betaw, S.T., Gebrehiwot, N.T., et al.: Knowledge, attitude, and practice of selfmedication with antibiotics among community residents in Addis Ababa, Ethiopia. Expert Rev. Anti Infect Ther. 17(6), 459-466 (2019). https://doi.org/10.1080/14787210.2019.1620105

20. Peng, D., Wang, X., Xu, Y., Sun, C., Zhou, X.: Antibiotic misuse among university students in developed and less developed regions of China: a cross-sectional survey. Glob. Health Action 11(1), 1496973 (2018). https://doi.org/10.1080/16549716.2018. 1496973

21. Aleem, M.A., Rahman, M., Ishfaq, M., Mehmood, K., Ahmed, S.S.: Determinants of antibiotics misuse by the parents in children: a survey from Northern Region of Saudi Arabia. Bangladesh J. Child Health 40(2), 64-71 (2016)

22. Hu, J., Wang, Z.: In-home antibiotic storage among Australian Chinese migrants. Int. J. Infect. Dis. 26, 103-106 (2014). https:// doi.org/10.1016/j.ijid.2014.04.017

23. Grigoryan, L., Monnet, D.L., Haaijer-Ruskamp, F.M., Bonten, M.J., Lundborg, S., Verheij, T.J.: Self-medication with antibiotics in Europe: a case for action. Curr. Drug Saf. 5(4), 329-332 (2010). https://doi.org/10.2174/157488610792246046

24. De Sanctis, V., Soliman, A.T., Daar, S., Di Maio, S., Elalaily, R., Fiscina, B., et al.: Prevalence, attitude and practice of selfmedication among adolescents and the paradigm of dysmenorrhea self-care management in different countries. Acta Biomed. 91(1), 182-192 (2020). https://doi.org/10.23750/abm.v91i1.9242

25. Xu, R., Mu, T., Wang, G., Shi, J., Wang, X., Ni, X.: Self-medication with antibiotics among university students in LMIC: a systematic review and meta-analysis. J. Infect. Dev. Countries 13(8), 678-689 (2019). https://doi.org/10.3855/jidc.11359

26. Bulabula, A.N.H., Dramowski, A., Mehtar, S.: Antibiotic use in pregnancy: knowledge, attitudes and practices among pregnant women in Cape Town South Africa. J. Antimicrob. Chemother. 75(2), 473-481 (2020). https://doi.org/10.1093/jac/dkz427

27. Wang, X., Lin, L., Xuan, Z., Li, L., Zhou, X.: Keeping antibiotics at home promotes self-medication with antibiotics among Chinese university students. Int. J. Environ. Res. Public Health 15(4), 687 (2018). https://doi.org/10.3390/ijerph15040687

28. Xu, Y., Lu, J., Sun, C., Wang, X., Hu, Y.J., Zhou, X.: A crosssectional study of antibiotic misuse among Chinese children in developed and less developed provinces. J. Infect. Dev. Countries 14(2), 129-137 (2020). https://doi.org/10.3855/jidc.11938

29. Jamhour, A., El-Kheir, A., Salameh, P., Hanna, P.A., Mansour, H.: Antibiotic knowledge and self-medication practices in a developing country: a cross-sectional study. Am. J. Infect. Control 45(4), 384-388 (2017). https://doi.org/10.1016/j.ajic.2016.11.026

30. The World Bank: Metadata glossary. https://databank.worldbank. org/metadataglossary/world-development-indicators/series/NY. ADJ.NNTY.CD. Accessed 1 Mar 2021

31. The World Bank: Price level ratio of PPP conversion factor (GDP) to market exchange rate. https://data.worldbank.org/indicator/PA. NUS.PPPC.RF?view=chart. Accessed 8 Feb 2021

32. The World Bank: GDP per capita, PPP (current international \$). https://data.worldbank.org/indicator/NY.GDP.PCAP.PP.CD. Accessed 8 Feb 2021

33. The World Bank: Adjusted net national income per capita (current US\$). https://data.worldbank.org/indicator/NY.ADJ.NNTY.PC. CD. Accessed 8 Feb 2021

34. The World Bank: World Bank country and lending groups, country classification. https://datahelpdesk.worldbank.org/knowledgeb ase/articles/906519-world-bank-country-and-lending-groups. Accessed 24 Feb 2021

35. World Health Organization: Countries. https://www.who.int/count ries/. Accessed 18 Feb 2021 
36. United Nations Educational Scientific and Cultural Organization: Education and literacy. http://uis.unesco.org/en/country/lb (2018). Accessed 21 Apr 2021

37. Orsini, N.: Weighted mixed-effects dose-response models for tables of correlated contrasts. Stata J. 21, 320 (2021)

38. Crippa, A., Discacciati, A., Bottai, M., Spiegelman, D., Orsini, N.: One-stage dose-response meta-analysis for aggregated data. Stat. Methods Med. Res. 28(5), 1579-1596 (2019). https://doi.org/10. $1177 / 0962280218773122$

39. World Health Organization: Global action plan on antimicrobial resistance. https://www.who.int/antimicrobial-resistance/publi cations/global-action-plan/en/. (2015). Accessed 21 Apr 2021

40. Modesti, P.A., Reboldi, G., Cappuccio, F.P., Agyemang, C., Remuzzi, G., Rapi, S., et al.: Panethnic differences in blood pressure in Europe: a systematic review and meta-analysis. PLoS ONE 11(1), e0147601 (2016). https://doi.org/10.1371/journal.pone. 0147601

41. Egger, M., Davey Smith, G., Schneider, M., Minder, C.: Bias in meta-analysis detected by a simple, graphical test. BMJ 315(7109), 629-634 (1997). https://doi.org/10.1136/bmj.315. 7109.629

42. Duval, S., Tweedie, R.: Trim and fill: a simple funnel-plot-based method of testing and adjusting for publication bias in metaanalysis. Biometrics 56(2), 455-463 (2000). https://doi.org/10. 1111/j.0006-341x.2000.00455.x

43. Chen, J., Sidibi, A.M., Shen, X., Dao, K., Maiga, A., Xie, Y., et al.: Lack of antibiotic knowledge and misuse of antibiotics by medical students in Mali: a cross-sectional study. Expert Rev. Anti Infect. Ther. 19, 1-8 (2020). https://doi.org/10.1080/14787 210.2021.1857731

44. Mate, I., Come, C.E., Goncalves, M.P., Cliff, J., Gudo, E.S.: Knowledge, attitudes and practices regarding antibiotic use in Maputo City, Mozambique. PLoS ONE 14(8), e0221452 (2019). https://doi.org/10.1371/journal.pone.0221452

45. Torres, K.S., Ochoa, A., Encalada, D., Quizhpe, A.: Prevalence of self-medication with antibiotics in the urban parishes of the city of Cuenca, 2016-2017 [Prevalencia de la automedicacion con antibioticos en las parroquias urbanas de la ciudad de Cuenca, 2016-2017]. Archivos Venezolanos de Farmacología y Terapéutica 36(4), 130-136 (2017)

46. Redzic, L., Zalihic, A.: Self-medication with antibiotics in family practice in patients and parents [Samomedikacija antibioticima među pacijentima]. Croat. J. Infect. [Infektološki glasnik] 38(3), 69-73 (2018)

47. Chang, F.R., Trivedi, P.K.: Economics of self-medication: theory and evidence. Health Econ. 12(9), 721-739 (2003). https:// doi.org/10.1002/hec.841

48. Mielck, A., Kiess, R., von dem Knesebeck, O., Stirbu, I., Kunst, A.E.: Association between forgone care and household income among the elderly in five Western European countries-analyses based on survey data from the SHARE-study. BMC Health Serv. Res. 9, 52 (2009). https://doi.org/10.1186/1472-6963-9-52

49. Mojtabai, R., Olfson, M.: Medication costs, adherence, and health outcomes among Medicare beneficiaries. Health Aff. (Millwood) 22(4), 220-229 (2003). https://doi.org/10.1377/ hlthaff.22.4.220

50. Piette, J.D., Heisler, M., Wagner, T.H.: Cost-related medication underuse among chronically ill adults: the treatments people forgo, how often, and who is at risk. Am. J. Public Health 94(10), 1782-1787 (2004). https://doi.org/10.2105/ajph.94.10.1782

51. Renahy, E., Parizot, I., Chauvin, P.: Health information seeking on the Internet: a double divide? Results from a representative survey in the Paris metropolitan area, France, 2005-2006. BMC Public Health 8, 69 (2008). https://doi.org/10.1186/1471-2458-8-69

52. Vanhaesebrouck, A., Vuillermoz, C., Robert, S., Parizot, I., Chauvin, P.: Who self-medicates? Results from structural equation modeling in the Greater Paris area, France. PLoS ONE 13(12), e0208632 (2018). https://doi.org/10.1371/journal.pone.0208632

53. World Health Organization: Global spending on health: a world in transition. https://www.who.int/health_financing/documents/ health-expenditure-report-2019/en/. (2019). Accessed 21 April 2021

54. Batista, A.D., Rodrigues, D.A., Figueiras, A., Zapata-Cachafeiro, M., Roque, F., Herdeiro, M.T.: Antibiotic dispensation without a prescription worldwide: a systematic review. Antibiotics (Basel) 9(11), 786 (2020). https://doi.org/10.3390/antibiotics9110786

55. Interagency Coordination Group on Antimicrobial Resistance: No time to wait: Securing the future from drug-resistant infections. Report to the secretary-general of the United Nations.: World Health Organization. https://www.who.int/antimicrobial-resis tance/interagency-coordination-group/final-report/en/. (2019). Accessed 21 Apr 2021

56. Higgins, J.P.: Commentary: heterogeneity in meta-analysis should be expected and appropriately quantified. Int. J. Epidemiol. 37(5), 1158-1160 (2008). https://doi.org/10.1093/ije/dyn204

57. National Research Council: Combining Information: Statistical Issues and Opportunities for Research. The National Academies Press, Washington, DC (1992)

58. Murad, M.H., Montori, V.M., Ioannidis, J.P.A., et al.: Fixedeffects and random-effects models. In: Guyatt, G., Rennie, D., Meade, M.O. (eds.) Users' Guide to the Medical Literature A Manual for Evidence-Based Clinical Practice, 3rd edn., p. 885. McGraw-Hill, New York (2015)

59. Mallah, N., Badro, D.A., Figueiras, A., Takkouche, B.: Association of knowledge and beliefs with the misuse of antibiotics in parents: a study in Beirut (Lebanon). PLoS ONE 15(7), e0232464 (2020). https://doi.org/10.1371/journal.pone.0232464

60. Abdelrahman, T.M., Al Saeed, M.S., Karam, R.A., Alkhthami, A.M., Alswat, O.B., Alzahrani, A.A., et al.: Misuse of antibiotics and antibiotic resistance: a public population-based health survey in al Taif- Saudi Arabia. WJPMR 3(2), 54-62 (2017)

61. Abobotain, A.H., Sheerah, H.A., Alotaibi, F.N., Joury, A.U., Mishiddi, R.M., Siddiqui, A.R., et al.: Socio-demographic determinants of antibiotic misuse in children. A survey from the central region of Saudi Arabia. Saudi Med. J. 34(8), 832-840 (2013)

62. Berlin, J.A.: Invited commentary: benefits of heterogeneity in meta-analysis of data from epidemiologic studies. Am. J. Epidemiol. 142(4), 383-387 (1995). https://doi.org/10.1093/oxfordjour nals.aje.a117645

63. Moktan, D., Shehnaz, S.I.: Factors driving self-medication with antimicrobials in Karaikal, Puducherry India. J. Pharmacol. Pharmacother. 11, 64-71 (2021). https://doi.org/10.4103/jpp.JPP_21_ 20

64. Elmahi, O.K.O., Balla, S.A., Khalil, H.A.: Self-medication with antibiotics and its predictors among the population in Khartoum Locality, Khartoum State, Sudan in 2018. Int. J. Trop. Dis. Health 41(4), 17-25 (2020). https://doi.org/10.9734/IJTDH/2020/v41i4 30267

65. Nusair, M.B., Al-Azzam, S., Alhamad, H., Momani, M.Y.: The prevalence and patterns of self-medication with antibiotics in Jordan: a community-based study. Int. J. Clin. Pract. 75, e13665 (2021). https://doi.org/10.1111/ijcp.13665

66. Ateshim, Y., Bereket, B., Major, F., Emun, Y., Woldai, B., Pasha, I., et al.: Prevalence of self-medication with antibiotics and associated factors in the community of Asmara, Eritrea: a descriptive cross sectional survey. BMC Public Health 19(1), 726 (2019). https://doi.org/10.1186/s12889-019-7020-x

67. Benameur, T., Al-Bohassan, H., Al-Aithan, A., Al-Beladi, A., AlAli, H., Al-Omran, H., et al.: Knowledge, attitude, behaviour of the future healthcare professionals towards the self-medication practice with antibiotics. J. Infect. Dev. Countries 13(1), 56-66 (2019). https://doi.org/10.3855/jidc. 10574 
68. Mukattasha, T.L., Alkhatatbeha, M.J., Andrawosa, S., Jaraba, A.S., AbuFarhab, R.K., Nusair, M.B.: Parental self-medication of antibiotics for children in Jordan. JPHSR (2019). https://doi. org/10.1111/jphs. 12331

69. Sun, C., Hu, Y.J., Wang, X., Lu, J., Lin, L., Zhou, X.: Influence of leftover antibiotics on self-medication with antibiotics for children: a cross-sectional study from three Chinese provinces. BMJ Open 9(12), e033679 (2019). https://doi.org/10.1136/bmjop en-2019-033679

70. Hu, Y., Wang, X., Tucker, J.D., Little, P., Moore, M., Fukuda, K., et al.: Knowledge, attitude, and practice with respect to antibiotic use among Chinese medical students: a multicentre crosssectional study. Int. J. Environ. Res. Public Health 15(6), 1165 (2018). https://doi.org/10.3390/ijerph15061165

71. Tong, S., Pan, J., Lu, S., Tang, J.: Patient compliance with antimicrobial drugs: a Chinese survey. Am. J. Infect. Control 46(4), e25-e29 (2018). https://doi.org/10.1016/j.ajic.2018.01.008

72. Albawani, S.M., Hassan, Y.B., Abd-Aziz, N., Gnanasan, S.: Self-medication with antibiotics in Sana'a City, Yemen. Trop. J. Pharm. Res. 16(5), 1195 (2017). https://doi.org/10.4314/tjpr. v16i5.30

73. Erku, D.A., Mekuria, A.B., Belachew, S.A.: Inappropriate use of antibiotics among communities of Gondar town, Ethiopia: a threat to the development of antimicrobial resistance. Antimicrob. Resist. Infect. Control 6, 112 (2017). https://doi.org/10.1186/ s13756-017-0272-2

74. Gebrekirstos, N.H., Workneh, B.D., Gebregiorgis, Y.S., Misgina, K.H., Weldehaweria, N.B., Weldu, M.G., et al.: Non-prescribed antimicrobial use and associated factors among customers in drug retail outlet in Central Zone of Tigray, Northern Ethiopia: a crosssectional study. Antimicrob. Resist. Infect. Control 6, 70 (2017). https://doi.org/10.1186/s13756-017-0227-7

75. Gillani, A.H., Ji, W., Hussain, W., Imran, A., Chang, J., Yang, C., et al.: Antibiotic self-medication among non-medical university students in Punjab, Pakistan: a cross-sectional survey. Int. J. Environ. Res. Public Health 14(10), 1152 (2017). https://doi.org/10. 3390/ijerph14101152

76. Hassali, M.A., Arief, M., Saleem, F., Khan, M.U., Ahmad, A., Mariam, W., et al.: Assessment of attitudes and practices of young Malaysian adults about antibiotics use: a cross-sectional study. Pharm. Pract. (Granada) 15(2), 929 (2017). https://doi.org/10. 18549/PharmPract.2017.02.929

77. Kajeguka, D.C., Moses, E.A.: Self-medication practices and predictors for self-medication with antibiotics and antimalarials among community in Mbeya City, Tanzania. Tanzan. J. Health Res. (2017). https://doi.org/10.4314/thrb.v19i4.6

78. Kurniawan, K., Posangi, J., Rampengan, N.: Association between public knowledge regarding antibiotics and self-medication with antibiotics in Teling Atas Community Health Center East Indonesia. Med. J. Indones. 25, 62-69 (2017). https://doi.org/10.13181/ mji.v26i1.1589

79. Nuñez, M., Tresierra-Ayalab, M., Gil-Olivares, F.: Antibiotic selfmedication in university students from Trujillo, Peru. Medicina Universitaria 18(73), 205-209 (2017). https://doi.org/10.1016/j. rmu.2016.10.003

80. Senadheera, G.P., Sri Ranganathan, S., Gunawardane, N.S., Fernando, G.H., Fernandopulle, B.M.: Practice of self-medication with antibiotics in the Colombo district, Sri Lanka. Ceylon Med. J. 62(1), 70-72 (2017). https://doi.org/10.4038/cmj.v62i1.8439

81. Bilal, M., Haseeb, A., Khan, M.H., Arshad, M.H., Ladak, A.A., Niazi, S.K., et al.: Self-medication with antibiotics among people dwelling in rural areas of Sindh. J. Clin. Diagn. Res. 10(5), 08-13 (2016). https://doi.org/10.7860/JCDR/2016/18294.7730

82. Zhu, X., Pan, H., Yang, Z., Cui, B., Zhang, D., Ba-Thein, W.: Selfmedication practices with antibiotics among Chinese university students. Public Health 130, 78-83 (2016). https://doi.org/10. 1016/j.puhe.2015.04.005

83. Ding, L., Sun, Q., Sun, W., Du, Y., Li, Y., Bian, X., et al.: Antibiotic use in rural China: a cross-sectional survey of knowledge, attitudes and self-reported practices among caregivers in Shandong province. BMC Infect Dis. 15, 576 (2015). https://doi.org/ 10.1186/s12879-015-1323-Z

84. Gebeyehu, E., Bantie, L., Azage, M.: Inappropriate use of antibiotics and its associated factors among urban and rural communities of Bahir Dar City administration, Northwest Ethiopia. PLoS ONE 10(9), e0138179 (2015). https://doi.org/10.1371/journal. pone. 0138179

85. Yousif, M.A., Abubaker, I.E.: Prevalence, determinants and practices of self-medication with antibiotics: a population based survey in Taif, Kingdom of Saudi Aarabiaksa. Int. J. Res. Pharm. Sci. 5(2), 51-56 (2015)

86. Cheaito, L., Azizi, S., Saleh, N., Salameh, P.: Assessment of selfmedication in population buying antibiotics in pharmacies: a pilot study from Beirut and its suburbs. Int. J. Public Health 59(2), 319-327 (2014). https://doi.org/10.1007/s00038-013-0493-y

87. Eticha, T., Araya, H., Alemayehu, A., Solomon, G., Ali, D.: Prevalence and predictors of selfmedication with antibiotics among Adi-haqi Campus students of Mekelle University, Ethiopia. IJPSR 5(10), 678 (2014)

88. Lv, B., Zhou, Z., Xu, G., Yang, D., Wu, L., Shen, Q., et al.: Knowledge, attitudes and practices concerning self-medication with antibiotics among university students in western China. Trop. Med. Int. Health 19(7), 769-779 (2014). https://doi.org/10.1111/tmi. 12322

89. Mihretie, T.M.: Self-Medication Practices with Antibiotics Among Urban Dwellers of Bahir Dar Town, North West Ethiopia. Addis Ababa University, Addis Ababa (2014)

90. Shah, S.J., Ahmad, H., Rehan, R.B., Najeeb, S., Mumtaz, M., Jilani, M.H., et al.: Self-medication with antibiotics among nonmedical university students of Karachi: a cross-sectional study. BMC Pharmacol. Toxicol. 15, 74 (2014). https://doi.org/10.1186/ 2050-6511-15-74

91. Widayati, A., Suryawati, S., de Crespigny, C., Hiller, J.E.: Self medication with antibiotics in Yogyakarta City Indonesia: a cross sectional population-based survey. BMC Res. Notes 4, 491 (2011). https://doi.org/10.1186/1756-0500-4-491

92. Hadi, U., Duerink, D.O., Lestari, E.S., Nagelkerke, N.J., Werter, S., Keuter, M., et al.: Survey of antibiotic use of individuals visiting public healthcare facilities in Indonesia. Int. J. Infect. Dis. 12(6), 622-629 (2008). https://doi.org/10.1016/j.ijid.2008.01.002

93. Al-Azzam, S.I., Al-Husein, B.A., Alzoubi, F., Masadeh, M.M., Al-Horani, M.A.: Self-medication with antibiotics in Jordanian population. Int. J. Occup. Med. Environ. Health 20(4), 373-380 (2007). https://doi.org/10.2478/v10001-007-0038-9

94. Sawair, F.A., Baqain, Z.H., Abu Karaky, A., Abu, E.R.: Assessment of self-medication of antibiotics in a Jordanian population. Med. Princ. Pract. 18(1), 21-25 (2009). https://doi.org/10.1159/ 000163041

95. Awad, A., Eltayeb, I., Matowe, L., Thalib, L.: Self-medication with antibiotics and antimalarials in the community of Khartoum State, Sudan. J. Pharm Pharm Sci. 8(2), 326-331 (2005)

Publisher's Note Springer Nature remains neutral with regard to jurisdictional claims in published maps and institutional affiliations. 